\title{
A precarização do trabalho em foco: rebatimentos para os assistentes sociais do Judiciário
}

\author{
The precarious work's discussion: \\ repercussions for social workers in Judiciary
}

\author{
Bárbara Leite Pereira Colombi \\ Mestre em Política Social pela Universidade Federal do Espírito Santo, \\ Vitória/ES, Brasil. Assistente Social do Tribunal de Justiça do Espírito Santo. \\ barbarapereira@gmail.com
}

\begin{abstract}
Resumo: Este artigo faz parte de uma conexão entre o resultado da pesquisa do mestrado em Política Social da Universidade Federal do Espírito Santo (Ufes) e a inserção, enquanto assistente social, no ambiente laboral do Poder Judiciário. O objetivo é desvendar de que forma o profissional de Serviço Social, inserido em um espaço onde os direitos laborais estão minimamente garantidos, podem, no sistema capitalista de produção, assumir também características de um trabalho precário.
\end{abstract}

Palavras-chave: Capitalismo. Precarização do trabalho. Serviço Social. Judiciário.

\begin{abstract}
This article is part of a connection between the search result of master in Social Policy at the Federal University of Espírito Santo (Ufes), and insertion, while social worker, in the Judiciary. The purpose of this article is to reveal how the professional social work inserted into a space where labor rights are minimally secured may, in the capitalist system of production, also take characteristics of precarious work.
\end{abstract}

Keywords: Capitalism. Labor's precariousness. Social Worker. Judiciary.

\section{Introdução}

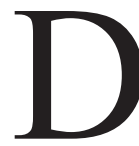

entro da própria dinâmica inerente à problemática que envolve o mundo do trabalho, vários termos são cunhados no intuito de explicar as transformações decorrentes do modo de produção capitalista e que afetam diretamente a classe trabalhadora; uma dessas designações se refere ao que muitos autores têm denominado precarização do trabalho.

No entanto, embora essa expressão tenha ganhado crescente espaço no debate contemporâneo, vários autores não a problematizam, muito menos a conceituam, 
criando a impressão de subentendimento e até mesmo de um conceito implícito, tácito à problemática do trabalho. Porém um uso descuidado do termo precarização do trabalho pode ocasionar uma superficialidade acerca do tema, impedindo-nos de alcançar o cerne da temática em questão. Outro aspecto vultoso a ser considerado com relação ao debate da precarização do trabalho é o aspecto do novo, do marco histórico recente, como se o surgimento estivesse interligado com o advento da acumulação flexível, em meados da década de 1990, que trouxe, entre outras consequências, a desregulamentação dos direitos laborais.

Este artigo pretende abarcar ainda a compreensibilidade por parte dos planejadores, avaliadores e executores no âmbito da política social, de que $o$ trabalho precário, embora presente no discurso trivial destes, não se revela como novidade e passível de alteração através de um direcionamento focalizado e pontual, mas sim de uma orientação que considere a necessidade de uma transformação sistêmica para atingirmos formas de sociabilidade que superem os meandros da relação de exploração entre a classe burguesa ante a operária.

Pois bem, quanto ao objetivo principal do estudo, iremos analisar do que se trata o fenômeno da precarização do trabalho no sistema capitalista de produção e os rebatimentos para o Serviço Social judiciário. Para isso, no primeiro momento, iremos recorrer à história com o fito de identificar se historicamente o modo de produção capitalista, em sua essência, deixou em algum momento de apresentar traços característicos de precariedade. Na segunda parte averiguaremos se existe ou não similaridade entre o termo precarização do trabalho com a flexibilidade e intensificação do trabalho, a partir da leitura de David Harvey e Sadi Dal Rosso; por último, traremos à baila a discussão para um recorte específico (os rebatimentos para o assistente social inserido no sociojurídico).

No que se refere ao método, esse trabalho visa dar visibilidade a um aspecto crucial no processo de consolidação do sistema capitalista de produção: as injustiças vivenciadas pela classe trabalhadora. E essa classe é aqui considerada como a estruturante, a explorada e injustiçada dentro da ordem sistêmica em que vivemos, mas ao mesmo tempo é a única capaz de transformar, alterar essa realidade e, acima de tudo, revolucionar. Ao ditar essas diretivas, assume-se peremptoriamente o caráter marxista deste estudo, por ser Marx o único autor que concederá os elementos necessários e suficientes para adentrarmos na essência do debate referente ao termo precarização do trabalho. 
Todo caminho implica necessariamente uma direção e um ponto de partida, e é preciso salientar que o rumo assumido neste trabalho assume uma postura composta tanto de um ideal transformador quanto do lugar dos trabalhadores no sistema capitalista. Demonstrar as contradições engendradas no processo de produção capitalista faz parte do que se pretende aprofundar neste trabalho. Trata-se de considerar que além da não absorção integral dos trabalhadores, essa forma de organização econômica extirpa do trabalhador inserido seus direitos e segurança. Essa direção assume pressupostos defendidos por Marx, que, segundo Netto (2011, p. 11), "foi um pensador que colocou, na sua vida e na sua obra, a pesquisa da verdade a serviço dos trabalhadores e da revolução socialista".

Assim, as premissas para compreeder as transformações que vêm ocorrendo no mundo do trabalho nas últimas décadas estão ancoradas na contextualização de aspectos intrínsecos ao sistema capitalista de produção, quais sejam: o processo de produção, acumulação e apropriação da riqueza. Portanto, inserir os trabalhadores nesse processo consiste em vinculá-los dentro de uma lógica organizativa caracterizada pela exploração intensa da força de trabalho.

Partindo-se da premissa de que a questão norteadora dessa pesquisa consiste em desvelar quais as características próprias do termo precarização do trabalho no sistema capitalista de produção, os pressupostos para apreensão desse problema de pesquisa engendrarão as categorias da totalidade, contradição e mediação. Afinal, para Marx, "a sociedade burguesa é uma totalidade concreta. Não é um 'todo' constituído por "partes' funcionalmente integradas" (Netto, 2011, p. 56) Torna-se, por isso, importante mencionar neste momento que a pesquisa bibliográfica será o meio do qual se valerá "o pesquisador para "apoderar-se da matéria" (Netto, 2011, p. 26). E, nessa perspectiva, difere da revisão bibliográfica, "uma vez que vai além da simples observação de dados contidos nas fontes pesquisadas, pois imprime sobre eles a teoria, a compreensão crítica do significado neles existente" (Lima e Mioto, 2007, p. 46).

Não podemos, ainda, deixar de mencionar o caráter histórico dessa pesquisa, enquanto método de procedimento: "[...] o método histórico preenche os vazios dos fatos e acontecimentos, apoiando-se em um tempo, mesmo que artificialmente reconstruído, que assegura a percepção da continuidade e do entrelaçamento dos fenômenos" (Lakatos e Marconi, 2010, p. 89).

Por último, devemos nos ater ao fato de que a hipótese desta pesquisa é a de considerar que o capitalismo, da maneira como a história ilustra, impôs e impõe 
em suas relações de classes sempre traços de fragilidade e precariedade para os trabalhadores. Esse é o ponto-chave deste artigo junto com uma ilustração, em que, teoricamente, a precarização do trabalho deixaria de existir.

\section{A precarização do trabalho em foco}

Para iniciarmos e de certa forma continuarmos a discussão que dará forma ao segundo tópico deste artigo foi necessário elencar e discorrer tanto sobre a intensificação quanto sobre a flexibilização do trabalho. Em primeiro lugar, sempre é importante lembrar que "o valor da força de trabalho compreende o valor das mercadorias necessárias para reproduzir o trabalhador, ou seja, para perpetuar a classe trabalhadora" (Marx, 2012, p. 307). Dessa forma, o trabalhador aufere como resultado de sua labuta somente o necessário para se reproduzir, para estar de prontidão no dia seguinte até o momento em que o capital dele precisar.

Acrescentamos ainda que embora Marx (2012) tenha pontuado sobre a reprodução do trabalhador diante do que este recebe em troca da venda de sua força de trabalho, para Marini (2005) até mesmo essa reprodução é prejudicada, na medida em que o que se recebe é insuficiente para essa própria reprodução do trabalhador. Segundo a visão do autor, a força de trabalho passa, por isso, por uma superexploração.

Para Marx (2012, p. 311), "a experiência mostra geralmente ao capitalista que existe uma população excedente em relação às necessidades momentâneas do capital de expandir o valor". A partir dessa premissa, partiremos, primeiramente, para a análise do que vem a ser a flexibilização das relações de trabalho.

Primeiro, é importante ponderar que a utilização do termo flexível, dentro dos moldes aplicados na atualidade, emergiu logo após um contexto histórico em que a produção era considerada extremamente rígida, com data inicial próxima de 1914, conhecida como fordismo. Essa forma organizativa precedia de um "maior esforço coletivo até para criar, com velocidade sem precedentes e com uma consciência de propósito sem igual na história, um novo tipo de trabalhador e um novo tipo de homem" (Harvey, 2007, p. 121). Além do aspecto produtivo em si, o fordismo previa também a necessidade de dar renda e tempo de consumo aos trabalhadores "para que consumissem os produtos produzidos em massa que as corporações estavam por fabricar em quantidades cada vez maiores" (idem, p.122). 
Quanto ao papel do Estado nesse contexto, a atuação se baseava na consolidação do regime de produção em evidência. A legitimação de seu poder, de acordo com Harvey (2007, p. 133), "dependia cada vez mais da capacidade de levar os benefícios do fordismo a todos e de encontrar meios de oferecer assistência médica, habitação e serviços educacionais adequados em larga escala, mas de modo humano e atencioso".

Partindo-se do pressuposto marxista de posicionar a organização material e econômica da sociedade em sua estrutura, que logo se relaciona de forma dialética com os pressupostos ideológicos e institucionais, teremos na acumulação flexível um aspecto efetivamente partícipe da vida do trabalhador: a insegurança. É como se a partir do molde estabelecido na produção econômica, o rebatimento da instabilidade e da fluidez também encontrasse terreno na relação de exploração perante a classe trabalhadora. Essa insegurança é manifestada por vias diversas, seja através da vinculação do contrato trabalhista e/ou cortes regulamentares de trabalho, seja através do enfraquecimento organizativo de luta. Essa desorganização, todavia, não rebate simultaneamente para o capital: à medida que se desorganizam/flexibilizam as relações de trabalho, de consumo e de armazenamento, o capitalismo se fortalece e se organiza, imperando seus anseios.

De acordo com Harvey (2002, p. 150-151),

o mais interessante na atual situação é a maneira como o capitalismo está se tornando cada vez mais organizado através da dispersão, da mobilidade geográfica e das respostas flexíveis nos mercados de trabalho, nos processos de trabalho e nos mercados de consumo, tudo isso acompanhado por pesadas doses de inovação tecnológica, de produto e institucional.

Além disso, na acumulação flexível há uma "redução do emprego regular em favor do crescente uso do trabalho em tempo parcial, temporário ou subcontratado". (Harvey, 2002, p. 143). O próprio uso da ciência sofreu consideráveis modificações, já que se focalizou na necessidade de ter "conhecimento da última técnica, do mais novo produto, da mais recente descoberta científica" para "se alcançar uma importante vantagem competitiva" (idem, p. 151).

Para a classe trabalhadora, portanto, os rebatimentos da acumulação flexível estão interligados preponderantemente com a flexibilização das relações laborais, 
envolvendo a apreensão de múltiplas tarefas, vinculações que refletem insegurança no trabalho e perdas de garantias trabalhistas. Após demarcarmos com clareza que essas consequências são reflexos do modo de acumulação flexível, analisaremos agora do que se trata a intensificação do trabalho.

Primeiramente é importante destacar que a intensificação do trabalho não está deslocada de nenhum momento histórico. Trata-se também de uma estratégia dentro do sistema capitalista a partir da luta firmada pelos trabalhadores em prol da regulamentação da jornada de trabalho. Segundo Rosso e Fortes (2008, p. 43), "o significado da questão da intensidade está no fato de que não se trata de um evento individualizado, e sim de uma condição geral do trabalho contemporâneo".

Teoricamente, se há uma diminuição das horas trabalhadas de dezesseis para oito, haveria uma diminuição da produção e, automaticamente, dos lucros. Entretanto, o prolongamento desmedido do uso da força de trabalho pelo capital possui limitações físicas, sociais e ainda provoca "reações na sociedade, que, ameaçada em suas raízes vitais, estabelece uma jornada normal de trabalho, legalmente limitada" (Marx, 2012, p. 467). A consequência dessa limitação implica necessariamente uma intensificação da produção, ou seja, "a capacidade de operar da força de trabalho está na razão inversa do tempo em que opera. Por isso, dentro de certos limites, o que se perde em duração, ganha-se em eficácia. Através do método de redistribuição, o capital induz o trabalhador a empregar realmente maior força de trabalho" (idem, p. 469); em outras palavras, intensificá-lo.

Para Rosso e Fortes (2008, p. 20), o primeiro fato a ser considerado dentro do estudo da intensidade se localiza no fato de que "ela se refere ao grau de dispêndio de energias realizado pelos trabalhadores na atividade concreta". Ou seja, o foco da análise dentro do estudo da intensificação do trabalho está nos trabalhadores. Os autores ainda ensinam que a intensificação consiste em "processos de quaisquer naturezas que resultam em um maior dispêndio das capacidades físicas, cognitivas e emotivas do trabalhador, com o objetivo de elevar quantitativamente ou melhorar qualitativamente os resultados" (idem, p. 23).

Assim, se a flexibilidade das relações laborais tem origem no modo de acumulação flexível e a intensificação está pautada preponderantemente em se produzir mais no mesmo espaço de tempo, temos que a precarização do trabalho perpassa esses dois processos. Como o termo estudado é utilizado similarmente com incerteza, efemeridade e instabilidade, viemos contrapor que dentro de qualquer contex- 
to histórico há sempre ocorrências dessas características. Afinal, é a forma de ser da normalidade sistêmica em sua organização econômica.

O que se pode evidenciar é que não há durabilidade em nenhuma condição estável dentro do capitalismo. O que há são momentos históricos que podem acarretar uma pseudoideia de constância, quando a única constância que efetivamente há é na presença de uma população supérflua e de uma classe explorada.

Ainda é preciso ter clareza de que a precarização, quando relacionada à inserção do trabalhador no mercado, pode traduzir uma ideia de que somente os trabalhadores incluídos são precarizados, e logo esquecemos aqueles que fazem parte de um mesmo processo mas se encontram desempregados.

É claro que também devemos nos ater ao fato de que as diversas formas contratuais utilizadas como estratégia do capital pressupõe uma característica de um momento histórico recente, e por isso, pode-se dizer, a utilização desse termo foi ampliada. No entanto, uma aplicação do termo precarização do trabalho dentro do âmbito da regulamentação trabalhista também pode polarizar o debate entre o aspecto social e o legal. A própria discussão sobre o trabalho assalariado e a necessária luta dos trabalhadores pela sua supressão parte da mesma argumentação de não reconhecimento dos trabalhadores em si, ou seja, daqueles "estáveis" e "instáveis", quando não há nenhuma estabilidade contratual dentro do capitalismo.

A precarização do trabalho é, por isso, própria da classe trabalhadora, sendo ao mesmo tempo processo e condição de existência do sistema capitalista. Por isso, à medida que o trabalhador tem sua força de trabalho superexplorada, nem mesmo sua inserção no mercado garante um rompimento com a pobreza.

A resposta do capital diante das ameaças de limitação dos seus lucros se encontra sumariamente interligada ao fato de recorrer com frequência à exploração do trabalhador, que se submete por suas próprias precisões a condições aviltantes de trabalho. Em qualquer esfera de inserção, os rebatimentos da precarização para a classe trabalhadora não possui "nem hora, nem lugar". Tudo se reflete, se conjuga e adquire a mesma feição de exploração. São as alternativas findadas pelo capital com o objetivo de alcançar seus superlucros. Para tanto, reestruturam a produção e trazem consequências diferenciadas para os trabalhadores. Ora as consequências assumem um caráter de ampliação da jornada de trabalho, intensificação da produtividade e queda dos salários; ora adquirem aspectos de insegurança, flexibilidade e fragilidade no emprego. São as estratégias intrínsecas ao sistema capitalista de 
produção, de se reestruturar atingindo diretamente a classe dos trabalhadores, que, ao serem explorados e posicionados após os interesses econômicos, tornam-se, como que automaticamente, precarizados.

\subsection{Rebatimentos para os assistentes sociais do Judiciário}

Ao tomarmos como base o posicionamento firmado de que a precarização do trabalho é um contorno próprio do sistema capitalista de produção, focalizaremos nossa análise dentro de um recorte no qual os assistentes sociais inseridos no campo sociojurídico absorvem esses rebatimentos através da sua atuação profissional. É importante pontuar que as reflexões neste artigo fazem parte de um olhar investigativo propiciado pela pesquisa científica elaborada no mestrado e também pela inserção profissional. $\mathrm{O}$ interesse em abordar este tema veio de um questionamento acadêmico sobre as formas em que o trabalho assume características de precariedade, mesmo quando o vínculo institucional possui caráter efetivo e de estabilidade.

Seria possível fazer uma menção a todos os servidores públicos, mas o recorte do objeto deste artigo, assistentes sociais no Judiciário, precisa ser analisado com cuidado, observadas as especificidades,${ }^{1}$ com o fito de propiciar debates tanto no universo do Serviço Social, quanto nos meandros institucionais. Vejamos que dentro da própria categoria existe um possível estigma quanto ao trabalho do assistente social no Judiciário, provavelmente por dois motivos: salário acima da média ${ }^{2}$ e efetivação da carga horária semanal de trinta horas na maioria dos estados da Federação. ${ }^{3}$

Essa compreensão acerca das diferenciações salariais gera, por princípio, uma dificuldade de reconhecimento dos trabalhadores entre si, como categoria e como

1. De acordo com Iamamoto (2007, p. 98), o trabalho do assistente social está situado "predominantemente no campo político-ideológico: o profissional é requerido para exercer funções de controle social e de reprodução da ideologia dominante junto aos segmentos subalternos, sendo seu campo de trabalho atravessado por tensões e interesses de classes".

2. Segundo o site do CFESS (Conselho Federal de Serviço Social), a média salarial da categoria é de $\mathrm{R} \$ 2.000,00$, embora existam projetos de lei na Câmara dos Deputados reivindicando um piso em torno de $\mathrm{R} \$ 4.000,00$.

3. É importante lembrar que a redução da carga horária não é sinônimo de diminuição da exploração, conforme verificado e explanado acerca da intensificação do trabalho. 
classe. Ou seja, a falta de identidade proporcionada pelas desigualdades salariais impulsiona, além de uma desmobilização, uma desarticulação política, social e ideológica.

Inseridos nesse contexto, os profissionais que atuam no campo sociojurídico assumem características de um trabalho precário interligado precipuamente à $d i$ nâmica institucional e à demanda profissional. Analisemos os dois em separado.

Com relação ao primeiro, o Judiciário assume vieses institucionais intensamente hierárquicos. Têm-se a figura do juiz de direito, que possui atribuições de poder para proferir determinações, e os servidores, que ora atuam com o fito de subsidiá-lo, ora de materializar as decisões prolatadas pelo mesmo. Ou seja, a base do Judiciário se movimenta pelas ações dos magistrados. São eles que administram o egrégio e direcionam os serviços prestados à população através do embasamento legislativo. Torna-se evidente, portanto, que todos os funcionários devem seguir as determinações dos juízes e, diferentemente de outros espaços, caso os trabalhadores não cumpram conforme enunciado, poderão vir a sofrer sanções, tanto penais (crime de desobediência, art. 330 do Código Penal) quanto administrativas (procedimento administrativo disciplinar).

Destarte, a formação do ambiente forense se caracteriza por fragilidades e inseguranças, na medida em que os servidores não podem descumprir o que lhes fora determinado. Observa-se, por vezes, que os funcionários se sentem intimidados, frustrados e constrangidos pela impossibilidade física, emocional e psíquica de exercerem na totalidade tudo o que lhe fora atribuído.

É importante mencionar que a formação técnica do direito não permite uma compreensão acerca dos instrumentos e processos de trabalho utilizados pelo assistente social, ocasionando, por diversas vezes, assimilações equivocadas acerca do trabalho executado pelo Serviço Social. Não diferente dos demais servidores, o assistente social é acionado pelo magistrado para subsidiá-lo em decisões que envolvem os meandros da questão social judicializada. ${ }^{4}$ Ocorre que tendo acesso a várias famílias, o profissional evidencia a necessidade de intervir e encaminhar os usuários para a rede socioassistencial e esbarra em um relacionamento tensionado pelos próprios direcionamentos firmados entre o Judiciário e o Executivo no trato

4. A questão social é expressão do processo de produção e reprodução da vida social na sociedade burguesa, da totalidade histórica concreta (Iamamoto, 2007, p. 114). 
cotidiano. Observa-se que pela dificuldade de dialogar, o Judiciário passa a determinar funcionalidades que o Executivo deve exercer e cumprir, e o estabelecimento dessa relação, pela via da obrigatoriedade, traz consequências significativas para a firmação de um trabalho coletivo e amistoso com a rede.

No que se refere à demanda profissional, torna-se mister listar as complexidades que envolvem o assistente social no contexto institucional do Judiciário. O primeiro quesito diz respeito à delimitação de prazos por parte dos magistrados para a emissão dos laudos e pareceres técnicos. Por vezes, agregando a necessidade de dar celeridade ao caso, principalmente os considerados urgentes, os juízes determinam prazos humanamente impossíveis de ser cumpridos. Entretanto, a questão paradoxal é que aquelas lides envolvendo maiores complexidades e urgências são as que necessitam de mais prazos para a execução.

Isso acontece pelo fato de o assistente social ser um profissional que posicionará os familiares dentro de um contexto social, econômico e político. Dessa forma, sua instrumentalidade técnica para cercar a realidade envolve dispositivos individualizados e também coletivos. O estudo acerca do caso abarca visitas domiciliares, atendimentos individuais, acesso à comunidade e, após a compreensibilidade desse invólucro, a emissão de um documento que é articulado teoricamente com o que fora observado e relatado.

Percebe-se que a dificuldade institucional em reconhecer a diferenciação do processo de trabalho do Serviço Social com a realidade vivida pelos demais servidores (expressivamente graduados em direito) desperta angústias e fragilidades no cotidiano laboral. Evidencia-se que o trabalho se encontra precarizado em uma dimensão correlacionada a posturas institucionalmente firmadas, no qual o assistente social se encontra subordinado e ao mesmo tempo com possibilidades interventivas. Segundo Iamamoto (2007, p. 96),

O Serviço Social dispõe de algumas características típicas de uma profissão liberal: a existência de uma autonomia relativa, por parte do assistente social, quanto à forma de condução de seu atendimento junto a indivíduos e/ou grupos sociais com os quais trabalha, o que requer o compromisso com valores e princípios éticos norteadores da ação profissional, explicitados no Código de Ética Profissional.

Em continuidade à análise da demanda, existe ainda outro fator que reveste o trabalho do assistente social no Judiciário, associado de forma precípua ao 
contexto do que lhe é demandado pelos magistrados para intervenção. Analiticamente, o Serviço Social é acionado pelo juiz com o objetivo de investigar uma situação específica contida nos autos. Por vezes o que se espera do profissional são respostas decisórias e taxativas para conduzir um embasamento dos direcionamentos que serão tomados dentro do trâmite judicial em questão.

Portanto, para efetivação das determinações originadas pela magistratura, o assistente social deve suprir as expectativas nele posicionadas. Essas expectativas assumem vieses de uma contenda em que se espera do profissional respostas diretas, preservação e auxílio aos familiares e assertividade acerca dos fatos, dentro de prazos determinados pelo juiz. $\mathrm{O}$ fato é que a não correspondência dessas aspirações reflete-se em sentimentos de frustração e ansiedade, impulsionando abatimento no relacionamento firmado entre o magistrado e o servidor.

Pois bem, diante de toda essa contextualização, novos questionamentos e apontamentos surgem e precisam efetivamente ser debatidos e discutidos com intensidade. É evidente que a inserção profissional em qualquer espaço revela contradições no trato cotidiano, e os caminhos para alteração da realidade assumem, essencialmente, a via coletiva da transformação. Torna-se necessário, entretanto, o aprofundamento teórico acerca dessa temática, principalmente para despertar a clareza de que a precarização do trabalho é partícipe do atual modelo econômico capitalista e ainda para trazer compreensibilidade das atribuições e funcionalidades do Serviço Social em seu espaço de atuação.

As demandas para o profissional estão cada vez mais intensificadas e com manifestações múltiplas de complexas contradições, impossibilitando uma articulação aprofundada com os movimentos sociais e com a rede, trazendo o risco de levar a atuação para parâmetros superficiais e desconexos com a conjuntura política, econômica e social.

Não se pode, naturalmente, esperar solução para essas circunstâncias enunciadas a partir de ações pontuais e deslocadas. É necessário que o Poder Judiciário assuma sua funcionalidade social e disponibilize meios e recursos humanos para sua aplicabilidade. É preciso reafirmar, portanto, “o desafio de tornar os espaços de trabalho do assistente social, espaços de fato públicos, alargando os canais de interferência da população na coisa pública, permitindo maior controle, por parte da sociedade, nas decisões que lhes dizem respeito" (Iamamoto, 2007, p. 143). Além disso, urge que as atribuições de caráter humanizado sejam assumido pelo direito, 
tanto no que se refere ao trato dos jurisdicionados, quanto na visão político-ideológica societária.

O que se observa ao se analisar a precarização do trabalho do assistente social no Judiciário faz parte de uma macroconjuntura, ou seja, a dinâmica institucional reproduz também os direcionamentos firmados no matiz econômico e social, objetivando a manutenção da ordem produtiva capitalista. Dessa forma, exigir dos servidores assistentes sociais produtividade incansável e cumprimento de prazos faz parte de uma lógica universal na qual os interesses econômicos estão posicionados acima dos trabalhadores, que se veem cada dia mais aviltados em seus ambientes laborais.

\section{Recebido em 28/4/2016 - Aprovado em 6/6/2016}

\section{Referências bibliográficas}

BRASIL. Lei n. 2.848, de 7 de dezembro de 1940. Conselho Federal de Serviço Social. Perguntas frequentes. Disponível em: $<$ http://www.cfess.org.br/visualizar/menu/local/perguntas-frequentes>. Acesso em: 14 jul. 2014.

HARVEY, D. Condição pós-moderna: uma pesquisa sobre as origens da mudança cultural. São Paulo: Loyola, 2002 e 2007.

IAMAMOTO, M. V. O Serviço Social na contemporaneidade: trabalho e formação profissional. 5. ed. São Paulo: Cortez, 2007.

LAKATOS, E. M.; MARCONI, M. A. Fundamentos de metodologia científica. 7. ed. São Paulo: Atlas, 2010.

LIMA, T. C. S.; MIOTO, R. C. T. Procedimentos metodológicos na construção do conhecimento científico: a pesquisa bibliográfica. Katalysis, v. 10, p. 35-45, 2007.

MARINI, R. M. Dialética da dependência, 1973. In: STÉDILE, João Pedro; TRASPADINI, Roberta (Orgs.). Ruy Mauro Marini: vida e obra. São Paulo: Expressão Popular, 2005. 
MARX, K. O capital: crítica da economia política: livro I. Rio de Janeiro: Civilização Brasileira, 2012.

NETTO, J. P. Introdução ao estudo do método de Marx. 1. ed. São Paulo: Expressão Popular, 2011.

ROSSO, S.; FORTES, J. A. A. S. (Orgs.). Condições de trabalho do limiar do século XXI. Brasília: Época, 2008. 